\title{
MAPPING OF HEAVY METAL CONTAMINATION CHARACTERISTICS USING CIAPRG METHODOLOGY
}

\author{
ALTAN, M. ${ }^{1}-$ AYYILDIZ, O $.^{1}-$ MALKOC, $\mathrm{S}^{2}-$ YAZICI, B. ${ }^{3}-$ KOPARAL, A. S. ${ }^{2 *}$ \\ ${ }^{1}$ Anadolu University, Science Faculty, Department of Physics, 26470, Eskişehir, Turkey. \\ (phone: +90-222-335-0580; fax: +90-222-320-4910) \\ ${ }^{2}$ Anadolu University, Applied Research Centre for Environmental Problems, 26555 Eskişehir, \\ Turkey. \\ (phone: +90-222-321-2528; fax: +90-222-321-2528) \\ ${ }^{3}$ Anadolu University, Science Faculty, Department of Statistics, 26470, Eskişehir, Turkey. \\ (phone: +90-222-335-0580; fax: +90-222-320-4910) \\ *Corresponding author \\ e-mail: askopara@anadolu.edu.tr \\ (Received $18^{\text {th }}$ Dec 2015; accepted $26^{\text {th }}$ Feb 2016)
}

\begin{abstract}
The aim of this study is to produce a digital contamination map which is interactively rectified with a database, projected and scaled. For this reason, a detailed investigation was conducted for an understanding of contamination dispersal characteristics in terms of the contribution of heavy metal concentrations, such as $\mathrm{mg} / \mathrm{kg}$ of $\mathrm{Cd}, \mathrm{Cr}, \mathrm{Cu}, \mathrm{Fe}, \mathrm{Mn}, \mathrm{Ni}, \mathrm{Pb}$ and $\mathrm{Zn}$ in a city center. CIAPRG Methodology (Contribution Independent of Amount through Positional Recoding and Grading) has been developed and used for the first time in this study by the authors in order to constitute a map of total heavy metal contamination distribution characteristics. Heavy metals from fifteen soil sample points, which were situated at different locations in the study area, were collected for chemical analysis. Data obtained by the chemical analysis was inserted into CIAPRG methodology. The majority of total heavy metal contribution is shown to be based on $\mathrm{Cu}, \mathrm{Mn}$ and $\mathrm{Ni}$. The effects of the contribution to pollution values which were recoded and graded, can be shown in relation to buildings, independent of the quantity of pollutant within the context of CIAPRG methodology. The resulting map designated that the mid and south-western parts of the study area were more intensive than the other parts in terms of heavy metal contamination. The graded contaminator values for soil and roadside dust were together compared with graded values for soil graded contaminator values, and roadside dust graded contaminator values, separately, using independent sample $t$ tests with the results being interpreted.
\end{abstract}

Keywords: CIAPRG methodology, heavy metal contamination distribution, roadside dust, soil

\section{Introduction}

Considering accelerated industrialization and urbanization, almost half of the world's population now lives in urban areas. Their dense activities result in an increasing amount of contaminants discharged into the urban environment. A variety of environmental problems have emerged, of which heavy metal pollution in urban soil is a major issue (Madrid et al., 2002; Tanner et al., 2008; Lu et al., 2010; Apeagyei et al., 2011; Xia et al., 2011). As typical contaminants in an urban environment, heavy metals are useful indicators of environmental pollution. For example, $\mathrm{Pb}, \mathrm{Cu}$ and $\mathrm{Zn}$ could be an indicator of traffic pollution. Most heavy metals, such as $\mathrm{Pb}, \mathrm{Cr}$ and $\mathrm{Cd}$, will continue to accumulate in an urban environment due to their non-biodegradability and their lasting nature. As a result, they are often termed 'chemical time bombs'. In urban areas, these 'bombs' have become a potential threat to human health and safety and have severely disturbed the natural geochemical cycle of the ecosystem. Metals have a 
direct influence on public health as they can easily enter the human body through dust ingestion, dermal contact or breathing (Lee et al., 2006; Kadi, 2009; Chen et al., 2010; Bućko et al., 2011).

The components of soils in a city center are affected significantly by human activity, even though soils are composed of mineral constituents, organic matter, living organisms and air and water that are of vital importance to human health. Vehicle exhaust particles, caused by traffic, contribute directly to heavy metal pollution (Lee et al., 2006; Shi et al., 2008; Christoforidis and Stamatis, 2009; Wei and Yang, 2010; Duoon and Lee, 2011).

In order to explain pollution characteristics precisely, a model should be constructed with all parameters included in the model. CIAPRG methodology has been developed and used in this study for the first time. The methodology in question identifies a related characteristics assessment concerning different pollutant sources.

\section{Materials and Methods}

\section{The study area}

The workspace covers an area of $2.8 \mathrm{~km}$ East-West and $1.3 \mathrm{~km}$ North-South (3.64 $\mathrm{km}^{2}$ ) and is $750-800 \mathrm{~m}$ above sea level. It is located on alluvial ground covering most of a housing area (Figure 1).

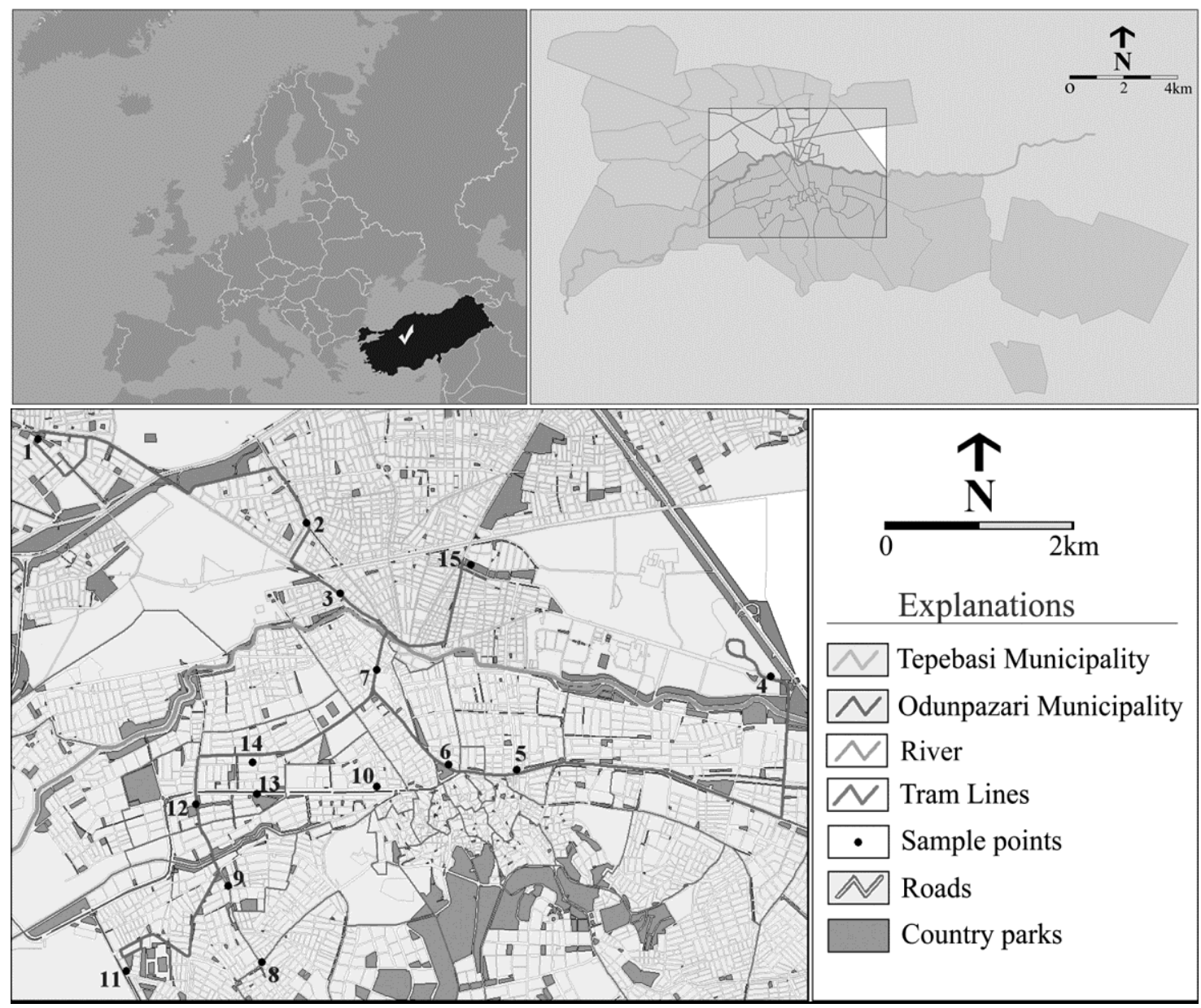

Figure 1. Location map of the study area and sampling locations 
This area contains geological units such as new alluvium, old alluvium and rock (Nefeslioglu et al., 2003). The new alluvium ground possesses a high earthquake risk due to its liquefaction potential (Ayday et al., 2001). These liquescent areas are concentrated on low speed grounds (Tun et al., 2004).

This new alluvium which fills Eskişehir lowland consists of loose sediment with no cementation between the particles. Generally, below this level, there is silt clay in which the silt percentage is higher. Certain areas below this level consist of a thick clay layer. At the lower layers, there is a sand level and below this there is silty sand. At the lower layers the sand percentage increases and gravelly sand is evident. The workspace comprises old alluvium in the north-west, rock in the south-east and new alluvium in between (Tun et al., 2004).

\section{Extensive CIAPRG methodology}

CIAPRG (Contribution Independent of Amount through Positional Recoding and Grading) methodology is a new method first used in this paper.

The aim of the method is to define the effects of the components of pollution, to model the locations of these components and to map them, taking into account the structural relationships between the components.

During the application part, firstly, the components of the pollution distribution to be mapped are defined. Each of these components causes pollution in the study area. These pollution values have a distribution and, by modeling, they are taken as a mean value of each layer. It is important to be cautious during the map construction stage. The processes of coordination and measurement should be planned, taking into account the aims of the study. The definitions of projection should be particularly defined considering the geographical properties and the location of the study area. Each variable which contributes to the pollution distribution and each component which constructs that contributor should be structured at a different layer where the locational relationships will be modeled. It is important that each of the layers be mapped separately in order to avoid confusion when denoting the map, examining one component distribution and evaluating the additive contribution of each contributor. The layers which have common components are rectified, projected, and structurally analyzed by location and modeled. When vector based mapping, in particular, is used, then the resolution is high.

The data base related to the numerical map, using strata contribution to the pollution, is constructed cautiously. The data base is a numerical platform used in modeling, analyzing the contribution of each component. The data base works interactively with the graphical unit. Each analysis result constructs a separate stratum on the graphical data. Similarly, the results of the analyses and modeling on the graphical data constructs a data set for new analyses.

Each component which contributes to the pollution in the area takes a score as the pollution contributor. At this stage, the vector based pollution distribution map layer is transformed by the grid based map layer. The extent of contribution to the pollution is defined by the relative contributions of other components. The contribution of each component depends on its own characteristics. These individual characteristic scores are written at the grid related coordinate and are correlated with their own characteristic information. Hence, it can be included in the calculations using the grid value. The contribution to the pollution of each component in the same coordinate is different to that of the other components. The important point here is that each grid value represents 
the degree of contribution to the pollution in the related coordinate. After this, the noted score at each grid is added to the other grid values at the related coordinate. Therefore, the recorded score at the related coordinate and grid will give a changeable result with the correlation of the extent of contribution to the resulting value which denotes the total result.

In the last stage, the amount of contribution to the pollution was recoded due to its contribution to the pollution and its own characteristic. The resulting map is a gridbased, measured, coordinated, projection-defined and data base interactive numerical map. On that map, for each of the coordinates, a grid based examination is possible. The contribution to pollution can be examined for every separate coordinate, and therefore, the contribution of the component itself can be obtained as a ratio or the contribution of all the components can be obtained as a total. In this way, the researcher can interpret the results in terms of the different contributions of the components.

\section{Sampling}

In this study, the workspace of the sampling area focused on Eskişehir city center. The heavy metal concentrations were used as input data for pollution maps to study the distribution of heavy metals in this urban area. A systematic sampling strategy was adopted to prove a sampling strategy over the entire workspace.

Gridding procedures were applied to the study area for homogeneous evaluation of the geographical data. Gridding was performed, based on a grid size of $5 \times 5 \mathrm{~m}^{2}$, using all of the input points available within a variable search radius. In this method, the closest point to the center of the grid unit is estimated. Heavy metals, which are highly enriched in soil and roadside dust were identified and compared.

The coordinates of the sample locations were recorded by GPS and the sampling grids are shown in Figure 1. An assessment of the overall contamination of the soil is based on the degree of contamination.

\section{Analytical methods}

Fifteen roadside dust and fifteen soil sites were selected in Eskişehir, including locations with a high density of buildings, main roads and tram lines (Figure 1). At each sampling site, roadside dust and soil samples of $\sim 1 \mathrm{~kg}$ were collected by sweeping, using a polyethylene brush and tray, during the dry season in June 2009. Sampling was performed on the first $10 \mathrm{~cm}$ below the surface of the soil along the roadside. All of these samples were initially air-dried in a laboratory, and then sieved through a $0.5 \mathrm{~mm}$ polyethylene sieve before being dried for 3 hours at $105^{\circ} \mathrm{C}$ (to a constant mass). A small portion, typically $500 \mathrm{mg}$ of dried and sieved samples, was transferred to a $10 \mathrm{ml}$ Teflon PFA (perfluoroalkoxy) vial. An aliquot of ultrapure $\mathrm{HNO}_{3}(10 \mathrm{~mL})$ was added and the cap of the vial was closed tightly. The acidified sample was kept at room temperature for 2-3 hours and then the bomb was heated at $175^{\circ} \mathrm{C}$ for 10 minutes. After cooling, the digests were passed through Whatman 41 filter paper (Whatman Company, UK). The digestion tubes were rinsed four times, passing through the filter, and the filters were made up to $100 \mathrm{~mL}$ volume using ultrapure water. Heavy metal concentrations were determined using soil and roadside dust samples of $500 \mathrm{mg}$ which were microwave digested (Cem Mars 5) (USEPA 2007). Finally, the content of heavy metals in the soil and roadside dust was determined by Inductively Coupled Plasma-Optic Emission Spectrometry (ICP-OES) (Varian 720 ES). 


\section{Software support}

In this study, two types of software were used for analyzing, modeling and developing maps. The software used for digitizing, mapping, spatial analysis and vector-based analyses was GeoMedia Professional, and for recode procedures, overlay analysis and other raster and grid-based analyses and modeling GeoMedia Grid Analysis was applied.

\section{Spatial Analysis with CIAPRG Methodology for Contribution to Map Layers}

Each of the heavy metal pollutants examined respectively was based on values which were obtained by soil and roadside dust analyses. Subsequently, digital dispersal maps were produced of the city center for each of the pollutants using this analyzed data. Each of contributors to heavy metal pollution exhibited different qualities. Therefore, initially, the concentration values of contributors were normalized in accordance with Equation 1.

Normalised Concentration was expressed by the following equations:

$$
N C_{i}=\frac{x_{i}-\mu}{\sigma}
$$

and $\mu$ is given by :

$$
\mu=\frac{1}{n} \sum_{i=1}^{n} x_{i}
$$

where $\boldsymbol{x}$ is a raw score to be standardized, $\boldsymbol{\mu}$ is the mean of the value of contributor and $\boldsymbol{\sigma}$ is the standard deviation of the value of the contributor.

Secondly, recoded maps were generated for every contributor in terms of characteristic pollution factors; average, $\%$ contribution, normalized concentration and exceeded risky factor. At this level of the study, equation 3 was used for every distribution map in order to grade the contribution degree to heavy metal pollution.

Contamination of heavy metal contributers $(\mathrm{CHC})$ was expressed by the following equations, where $\mathrm{NC}$ is Normalised Concentration, $\mathrm{C}$ is Contribution, Av is Average Value and CF is Coefficient Factor.

$$
C H C_{i}=\sum_{i=1}^{\mathbf{g}} N C_{i} \cdot C_{i} \cdot A v_{i} \cdot C F_{i}
$$

Finally, superimposed maps, used as traffic density volume maps and recoded contributor maps according to distributions of heavy metals with characteristic pollution factors, were also generated, classified and recoded. Equation 4 was also used for every distribution map, in order to generate and to grade total contamination of heavy metal contributors according to contribute to pollution. The final heavy metal pollution 
distribution map, generated using CIAPRG Methodology, included all heavy metal pollutant contributions.

The total contamination of the heavy metal contributers (TCHC) is expressed by the following equations:

$$
T C H C=\sum_{i=1}^{8} \prod_{j=1}^{4} X_{i j}
$$

Related parameters of heavy metals for i, 1,2,3,4,5,6,7 and 8 refer to $\mathrm{Cr}, \mathrm{Ni}, \mathrm{Fe}, \mathrm{Pb}$, $\mathrm{Mn}, \mathrm{Cd}, \mathrm{Cu}$ and $\mathrm{Zn}$ respectively. Related parameter of contaminations for $\mathrm{j}, 1,2,3,4$, refer to the relevant values of Normalized Concentraion (NC), Contribution of Contributor (C), and Coefficient Factor (CF) respectively, with TCHC as the Total Contamination of Heavy Metal Contributors. Equations 1-4 are considered by authors in terms of the CIAPRG Methodology in this study. The superimpose process in terms of contribution of heavy metal contamination as an example for only one grid, located at the same coordinate in each contribution map, is shown in Figure 2. This process was applied to each grid cell, located at the same coordinate for every contribution distribution map.

The final total contaminations of heavy metal contributers, generated using contributions thanks to scaled, rectified and projected heavy metal contributors, could be correctly superimposed with rectified high resolution satellite imagery.

\section{Results and Discussions}

When heavy metal pollution was evaluated for both the soil and roadside dust samples, Ni concentrations were found to be significantly above limit values at almost all sample points $(75 \mathrm{mg} / \mathrm{kg}$ ) (Malkoc et al., 2010). When pollution was graded, Ni was seen as most abundant for soil at $41.52 \%$, and for roadside dust $36.76 \%$. Cr was found as the second most abundant for soil at $18.57 \%$ and for roadside dust at $20.95 \%$. Although Fe was found as the third most abundant for soil at $16.93 \%$, it was found to be the least abundant for roadside dust at $0.20 \%$. It cannot be concluded that $\mathrm{Fe}$ is an abundant parameter, because the color of Eskisehir soil is brown, taking that color from Fe. A low ratio of $\mathrm{Fe}$ in roadside dust shows the probable Fe pollution. The reference values for $\mathrm{Fe}$ and $\mathrm{Mn}$ do not exist in soil pollution regulations, hence Environmental Protection Agency (EPA) standards (USEPA, 2004) were taken into account as reference values. For the soil samples, the contaminators can be arranged in order as follows: $\mathrm{Ni}>\mathrm{Cr}>\mathrm{Fe}>\mathrm{Cd}>\mathrm{Cu}>\mathrm{Mn}>\mathrm{Zn}>\mathrm{Pb}$. For the dust samples, they can be arranged in order as follows: $\mathrm{Ni}>\mathrm{Cr}>\mathrm{Cu}>\mathrm{Cd}>\mathrm{Zn}>\mathrm{Mn}>\mathrm{Pb}>\mathrm{Fe}$. Neglecting $\mathrm{Fe}$ at all sample points, the $\mathrm{Pb}$ ratio would be the lowest for both soil at $1.96 \%$ and for dust at $3.85 \%$. This does not exceed the limit values at any of the sample points $(300 \mathrm{mg} / \mathrm{kg})$. When $\mathrm{Cd}, \mathrm{Cu}, \mathrm{Mn}$ and $\mathrm{Zn}$ value orders were compared for soil and dust, the degree of the contaminators were seen to vary, but the limit values were not exceeded. The ratios of contaminators for the soil samples were, $\mathrm{Cd} 7.78 \%, \mathrm{Cu} 4.92, \mathrm{Mn} \mathrm{4.21 \%}$ and $\mathrm{Zn} \mathrm{4.12,} \mathrm{while} \mathrm{the} \mathrm{ratios}$ of contaminators for the roadside dust samples were, $\mathrm{Cu} 13.79 \%, \mathrm{Cd} 10.56 \%, \mathrm{Zn}$ $9.38 \%$ and $\mathrm{Mn} 4.51 \%$ (Table 1). 

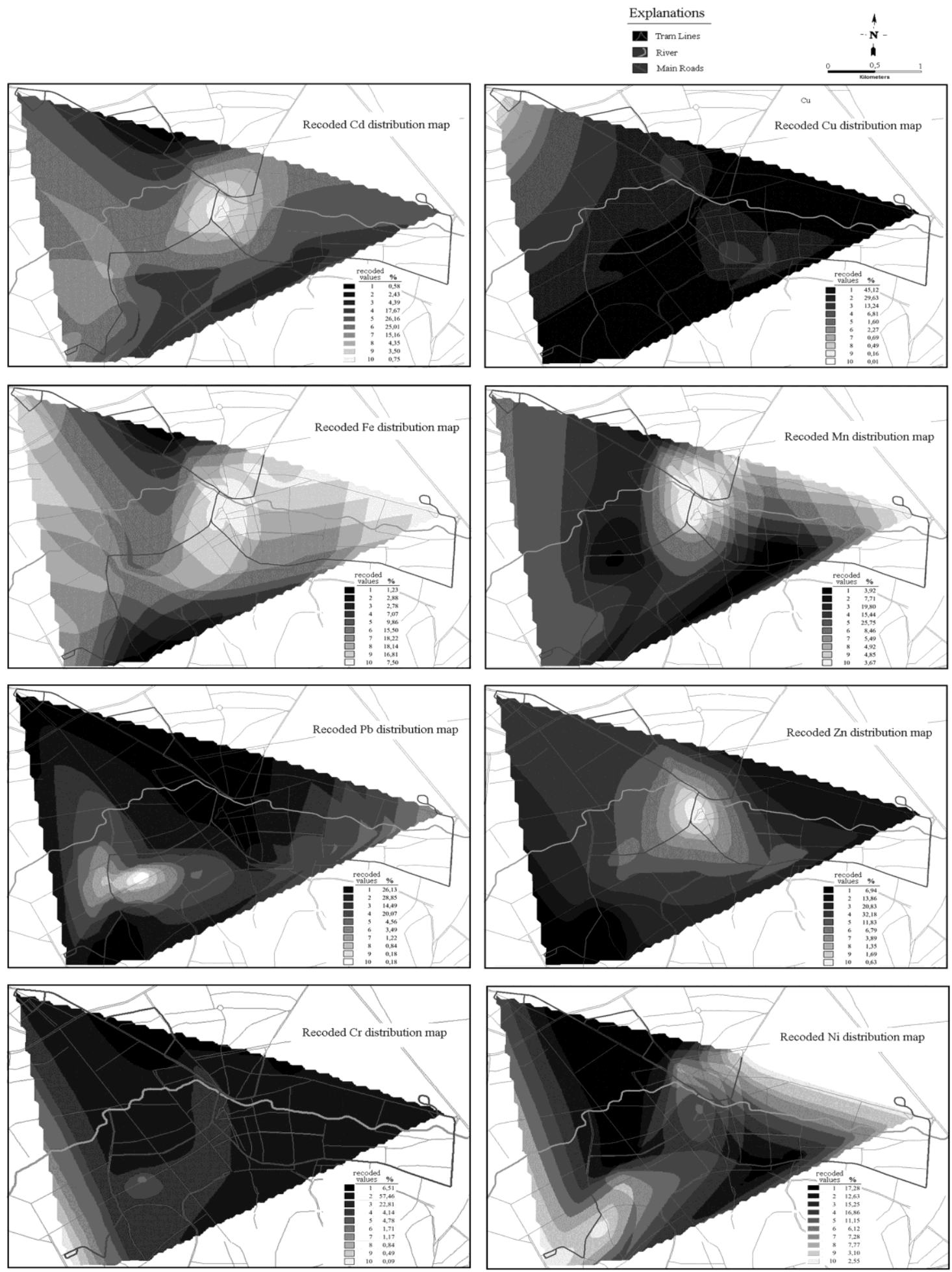

Figure 2. Graded heavy metal pollution distribution maps for soil and road dust

The most important result of this study is that none of parameter values exceeded the corresponding limit values for dust samples at three types of sample points; for only tram, only traffic and for both traffic and tram sample points. However, for the soil samples, those values were below the limits only at the sample points at both the traffic 
and tram lines. According to the results, vehicles and passing trams are not the only sources of pollution at the sample points in question. Also traffic density, vehicle duration time at traffic lights (different at almost all the sample points), volume of traffic, types of vehicles, road construction work, meteorological conditions, and wind direction may affect results.

Table 1. Contamination degrees for metals in soil and road dust

\begin{tabular}{lllllll}
\hline & \multicolumn{3}{c}{ Soil } & \multicolumn{3}{c}{ Road Dust } \\
\hline Metal & $\begin{array}{l}\text { Range } \\
(\mathrm{mg} / \mathrm{kg})\end{array}$ & $\begin{array}{l}\text { Average } \\
(\mathrm{mg} / \mathrm{kg})\end{array}$ & $\begin{array}{l}\text { Contribution } \\
(\%)\end{array}$ & $\begin{array}{l}\text { Range } \\
(\mathrm{mg} / \mathrm{kg})\end{array}$ & $\begin{array}{l}\text { Average } \\
(\mathrm{mg} / \mathrm{kg})\end{array}$ & $\begin{array}{l}\text { Contribution } \\
(\%)\end{array}$ \\
\hline $\mathrm{Cd}$ & $0.59-3.39$ & 1.23 & 7.78 & $0.60-1.99$ & 1.08 & 10.56 \\
$\mathrm{Cr}$ & $7.37-231.97$ & 97.85 & 18.57 & $34.98-132.73$ & 71.42 & 20.95 \\
$\mathrm{Cu}$ & $9.22-112.29$ & 36.31 & 4.92 & $16.25-274.80$ & 65.84 & 13.79 \\
$\mathrm{Fe}$ & $8809.17-39877.56$ & 20517 & 16.93 & $8636.57-24865.85$ & 153.14 & 0.2 \\
$\mathrm{Mn}$ & $243.65-571.37$ & 399.24 & 4.21 & $191.76-502.19$ & 276.81 & 4.51 \\
$\mathrm{Ni}$ & $8.84-299.47$ & 164.11 & 41.52 & $61.2-182.32$ & 94 & 36.76 \\
$\mathrm{~Pb}$ & $6.9-97.39$ & 30.92 & 1.96 & $11.13-113.61$ & 39.43 & 3.85 \\
$\mathrm{Zn}$ & $33.50-156.88$ & 65.18 & 4.12 & $28.79-250.65$ & 95.96 & 9.38 \\
$\begin{array}{l}\text { Degree of } \\
\text { contamination }\end{array}$ & $9119.25-41350.32$ & & 100 & $8981.29-26324.15$ & & 100 \\
\hline
\end{tabular}

The southern and western parts of Eskişehir city center were found to be more polluted than the other parts of the study area in terms of $\mathrm{Ni}$ and $\mathrm{Cr}$ concentration distributions, as shown in Figures 3 and Figure 4. Since we could not find any value which exceeded the critical limit for $\mathrm{Cd}, \mathrm{Cu}, \mathrm{Fe}, \mathrm{Mn}$ and $\mathrm{Zn}$, it was not necessary to calculate a Coefficient Factor for these heavy metals. In this process, the first original values of the contributors were used. These were then recalculated in terms of their contribution to total heavy metal pollution as layers, and then these values, graded according to their contribution to total pollution, were calculated as a percentage of the total area. These values, which were calculated, recoded and graded for each map, were generated for characterization of heavy metal pollution (Figure 5).

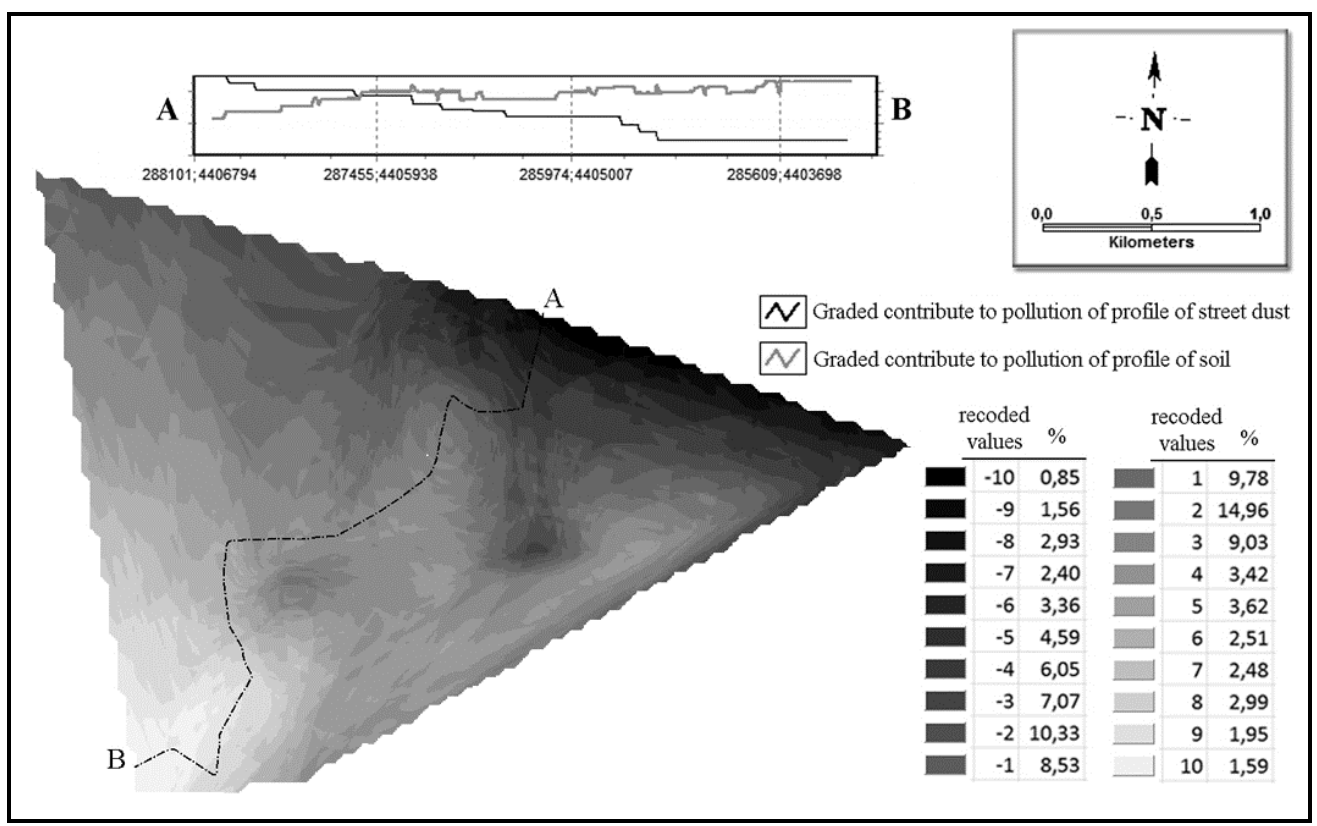

Figure 3. Contamination profiles of recoded values from soil and road dust 


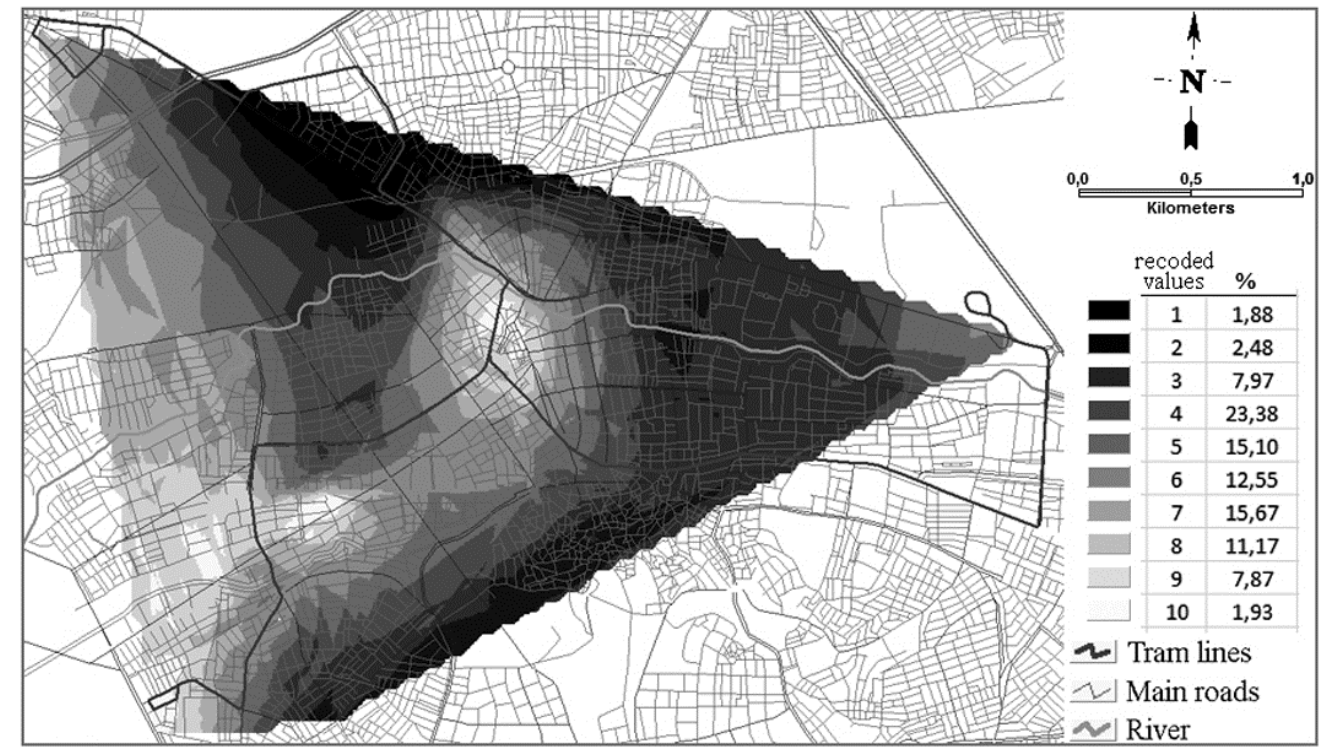

Figure 4. Digital map of the city center superimposed with graded pollution map

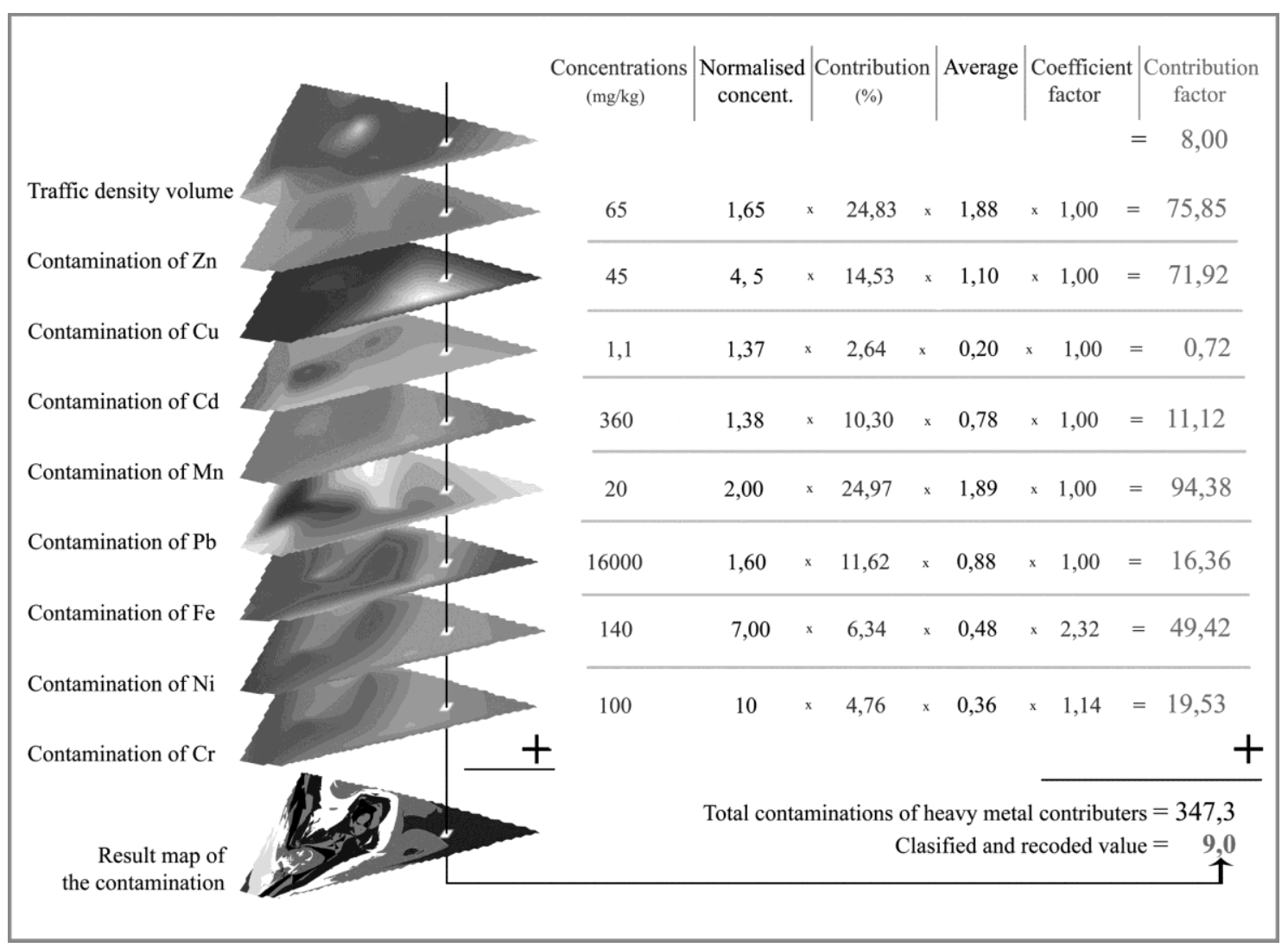

Figure 5. Example showing the superimposed process, in terms of contribution of heavy metal contamination, for one grid

Pollution distributions were mapped for soil and roadside dust separately, and then the percentage of pollution degrees were calculated on the total studied area (Figure 2). 
At this part of the study, the heavy metal pollution maps, generated for soil and roadside dust separately, were not used to determine a contribution to total pollution, because any contribution to pollution was caused not only by soil, but also roadside dust, at the same coordinates of the studied area and at the same points as grids on the digital map.

In order to determine total pollution, contribution values caused by both of the sources were collected at the same pool, and these were then recoded and graded in terms of a percentage contribution to total heavy metal pollution, instead of each source being evaluated individually (Table 2). Each contribution grade value of heavy metal pollution is shown in Table 2. Grey colored cells and bold written values refer to contributions of heavy metal pollution caused by roadside dust, and values written in ordinary font refer to contributions of heavy metal pollution caused by soil. For a grading contribution degree to total pollution for each contributor, all values of soil and roadside dust were graded and sorted at the same scale. Therefore, all of the graded values were mixed in terms of contribution to pollution (Table 2).

All of the pollutant contribution values were graded from 1 to $10 . \mathrm{Cu}, \mathrm{Mn}, \mathrm{Ni}$ and $\mathrm{Pb}$ elements in the soil and $\mathrm{Cd}, \mathrm{Cr}$ and $\mathrm{Fe}$ elements in the roadside dust were investigated by analyses to identify their contribution to the heavy metal pollution.

Related $\mathrm{Zn}$ values are approximately at the same percentage for the soil and the roadside dust (Figure 6).

\begin{tabular}{clll}
\hline & Soil $\%$ & Roadside dust & equal $\%$ \\
\hline $\mathrm{Cd}$ & $\mathbf{1 8 , 1}$ & $\mathbf{7 3 , 5 1}$ & $\mathbf{8 , 3 9}$ \\
\hline $\mathrm{Cr}$ & $\mathbf{2 1 , 4 7}$ & $\mathbf{5 8 , 2 2}$ & $\mathbf{2 0 , 3 1}$ \\
\hline $\mathrm{Cu}$ & 65,75 & 22,67 & 11,58 \\
\hline $\mathrm{Fe}$ & $\mathbf{3 8 , 2 6}$ & $\mathbf{4 8 , 4 2}$ & $\mathbf{1 3 , 3 2}$ \\
\hline $\mathrm{Mn}$ & 75,1 & 19,2 & 5,7 \\
\hline $\mathrm{Ni}$ & 65,43 & 23,05 & 11,52 \\
\hline $\mathrm{Pb}$ & 68,46 & 10,81 & 20,73 \\
\hline $\mathrm{Zn}$ & $\mathbf{4 1 , 3}$ & $\mathbf{4 1 , 3 5}$ & $\mathbf{1 7 , 3 5}$ \\
\hline
\end{tabular}

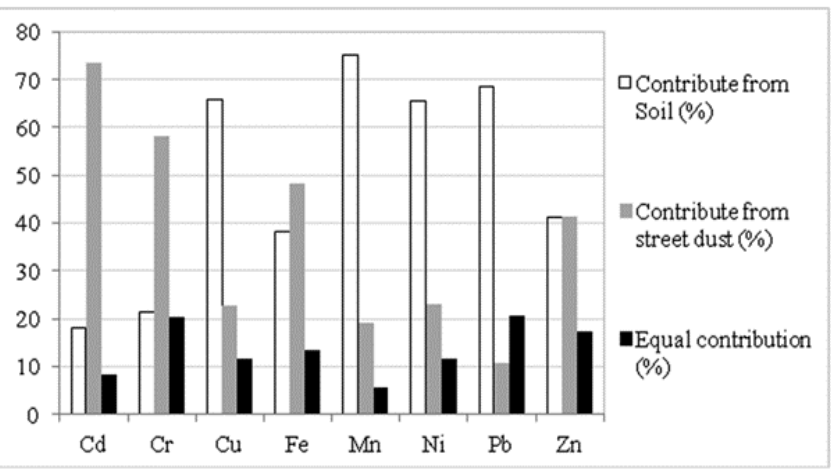

Figure 6. Percentage values for each pollutant contributing to pollution on entire study area

An AB-profile was obtained for only one tram line, in terms of explaining this difference visually. In the AB-profile, the bold grey solid line refers to the graded contribution to pollution values for soil, and the thin black solid line refers to the graded contribution to pollution values for roadside dust. A differentiation map was obtained by subtracting the graded values of contribution to pollution caused by roadside dust from the graded values of contribution to pollution caused by soil. Negative results mean that the contributions to pollution from roadside dust are more than that of soil. Because more pollution is caused by roadside dust at around point $\mathrm{A}$, the black thin solid line located at the top of the AB-profile approached point A. Due to the $x y=287455.4405938$ coordinate being located at the other side of the area, a bold grey line was drawn at the top of the AB-profile, close to point B. Heavy metal pollution in the soil increased in this part of the studied area (Figure 3).

In this part of the study, the graded data values for soil and roadside dust together were compared with the graded values for soil using an independent sample $t$ test. As a result of analyses, the difference between the soil and roadside dust values and the soil values for $\mathrm{Cd}$ $(\mathrm{p}=0.488), \mathrm{Mn}(\mathrm{p}=0.903), \mathrm{Pb}(0.948)$ were not found to be statistically significant. 
However, the differences in question were found to be statistically significant for $\mathrm{Cr}$ $(\mathrm{p}=0.016), \mathrm{Cu}(\mathrm{p}=0.000), \mathrm{Fe}(\mathrm{p}=0.020), \mathrm{Ni}(\mathrm{p}=0.013)$ and $\mathrm{Zn}(\mathrm{p}=0.000)$.

Table 2. Mixed and sorted pollution contribution values caused by soil and road dust

\begin{tabular}{|c|c|c|c|c|c|c|c|}
\hline $\mathrm{Cd}$ & $\mathrm{Cr}_{\mathrm{r}}$ & $\mathrm{Cu}$ & $\mathrm{Fe}$ & $\mathrm{Mn}$ & $\mathrm{Ni}$ & $\mathrm{Pb}$ & $\mathrm{Zn}$ \\
\hline 1 & 1 & 1 & 1 & 1 & 1 & 1 & 1 \\
\hline 1 & 1 & 1 & 1 & 1 & 1 & 1 & 1 \\
\hline 1 & 1 & 1 & 1 & 1 & 1 & 1 & 1 \\
\hline 2 & 1 & 1 & 1 & 1 & 1 & 1 & 1 \\
\hline 2 & 1 & 1 & 1 & 1 & 1 & 1 & 1 \\
\hline 2 & 1 & 1 & 1 & 1 & 1 & 1 & 1 \\
\hline 2 & 1 & 1 & 1 & 1 & 1 & 1 & 1 \\
\hline 2 & 1 & 1 & 1 & 1 & 1 & 1 & 1 \\
\hline 2 & 1 & 1 & 1 & 2 & 1 & 1 & 1 \\
\hline 2 & 1 & 1 & 1 & 2 & 1 & 1 & 1 \\
\hline 3 & 1 & 1 & 1 & 2 & 1 & 1 & 1 \\
\hline 3 & 1 & 1 & 1 & 2 & 1 & 1 & 1 \\
\hline 3 & 1 & 1 & 1 & 3 & 1 & 2 & 1 \\
\hline 3 & 1 & 1 & 1 & 4 & 1 & 2 & 1 \\
\hline 3 & 1 & 1 & 1 & 4 & 1 & 2 & 1 \\
\hline 3 & 1 & 1 & 1 & 4 & 1 & 2 & 1 \\
\hline 4 & 1 & 1 & 2 & 5 & 1 & 2 & 1 \\
\hline 4 & 1 & 1 & 2 & 5 & 1 & 3 & 1 \\
\hline 4 & 1 & 1 & 2 & 5 & 1 & 3 & 1 \\
\hline 4 & 1 & 1 & 2 & 5 & 1 & 3 & 1 \\
\hline 4 & 1 & 1 & 2 & 6 & 1 & 3 & 1 \\
\hline 5 & 1 & 1 & 2 & 6 & 1 & 3 & 1 \\
\hline 5 & 1 & 1 & 2 & 6 & 1 & 3 & 1 \\
\hline 5 & 1 & 2 & 2 & 6 & 1 & 4 & 1 \\
\hline 6 & 1 & 2 & 2 & 6 & 1 & 4 & 1 \\
\hline 6 & 1 & 2 & 3 & 6 & 1 & 4 & 1 \\
\hline 6 & 1 & 2 & 3 & 7 & 1 & 5 & 1 \\
\hline 6 & 1 & 2 & 4 & 7 & 1 & 5 & 1 \\
\hline 6 & 2 & 2 & 4 & 7 & 1 & 5 & 1 \\
\hline 7 & 2 & 2 & 4 & 7 & 1 & 5 & 1 \\
\hline 7 & 2 & 2 & 5 & 7 & 1 & 5 & 1 \\
\hline 8 & 2 & 2 & 5 & 8 & 1 & 5 & 1 \\
\hline 8 & 2 & 2 & 6 & 8 & 2 & 5 & 2 \\
\hline 8 & 3 & 2 & 6 & 8 & 3 & 6 & 2 \\
\hline 8 & 3 & 2 & 6 & 8 & 4 & 6 & 2 \\
\hline 8 & 4 & 2 & 7 & 8 & 4 & 6 & 2 \\
\hline 9 & 4 & 3 & 7 & 8 & 5 & 6 & 2 \\
\hline 9 & 5 & 3 & 7 & 9 & 6 & 6 & 2 \\
\hline 9 & 5 & 3 & 7 & 9 & 6 & 6 & 2 \\
\hline 9 & 5 & 3 & 7 & 9 & 7 & 7 & 2 \\
\hline 9 & 6 & 3 & 7 & 10 & 9 & 7 & 2 \\
\hline 10 & 7 & 3 & 8 & 10 & 10 & 7 & 2 \\
\hline 10 & 8 & 3 & 8 & & 10 & 7 & 2 \\
\hline 10 & 9 & 3 & 8 & & & 8 & 2 \\
\hline & 10 & 4 & 8 & & & 8 & 2 \\
\hline & & 4 & 8 & & & 8 & 3 \\
\hline & & 4 & 8 & & & 8 & 3 \\
\hline & & 5 & 9 & & & 8 & 4 \\
\hline & & 6 & 9 & & & 9 & 4 \\
\hline & & 6 & 9 & & & 9 & 4 \\
\hline & & 7 & 9 & & & 9 & 5 \\
\hline & & 8 & 10 & & & 9 & 5 \\
\hline & & 9 & 10 & & & 10 & 6 \\
\hline & & 10 & 10 & & & 10 & 6 \\
\hline & & & & & & & 7 \\
\hline & & & & & & & 7 \\
\hline & & & & & & & 8 \\
\hline & & & & & & & 9 \\
\hline & & & & & & & 9 \\
\hline & & & & & & & 10 \\
\hline & & & & & & & 10 \\
\hline
\end{tabular}


The soil and roadside dust contamination data set was also compared with the roadside dust contamination data set for the same heavy metals using their graded values. As a result of independent sample $t$ testing, the difference between the graded values for soil and roadside dust and the roadside dust data for $\mathrm{Cd}(\mathrm{p}=0.712), \mathrm{Mn}$ $(\mathrm{p}=0.735)$ and $\mathrm{Pb}(\mathrm{p}=0.199)$ were not found to be statistically significant. However, the difference between the graded values for soil and roadside dust contamination and roadside dust contamination for $\mathrm{Cr}(\mathrm{p}=0.005), \mathrm{Cu}(\mathrm{p}=0.011), \mathrm{Fe}(\mathrm{p}=0.019), \mathrm{Ni}$ $(\mathrm{p}=0.024)$ and $\mathrm{Zn}(\mathrm{p}=0.007)$ were found to be statistically significant.

Since the graded contaminator values together for roadside dust and soil were found to be greater than those for soil and roadside dust separately, these were taken into account in the digital mapping.

A digital map of the city center was superimposed with a distribution map, generated in terms of total pollution contributions from heavy metals in soil and roadside dust scaled on buildings (Figure 4).

In this way, the reformed superimposed map provided better visualization of the contributions of the heavy metal pollutants in the soil. This map also was used to study the relationship between metal enrichment in soils, roadside dust and related traffic volumes. Detailed heavy metal pollution distribution in soil of an urban area can be shown, based on buildings, in a similar manner.

The obtained final total pollution distribution map is scaled, rectified and projected; it was therefore, correctly and easily superimposed using high resolution satellite imagery. Hence, heavy metal pollution distribution was determined due to the characteristics of the contributors included and the effects of the embedded pollutants, based on buildings (Figure 7).

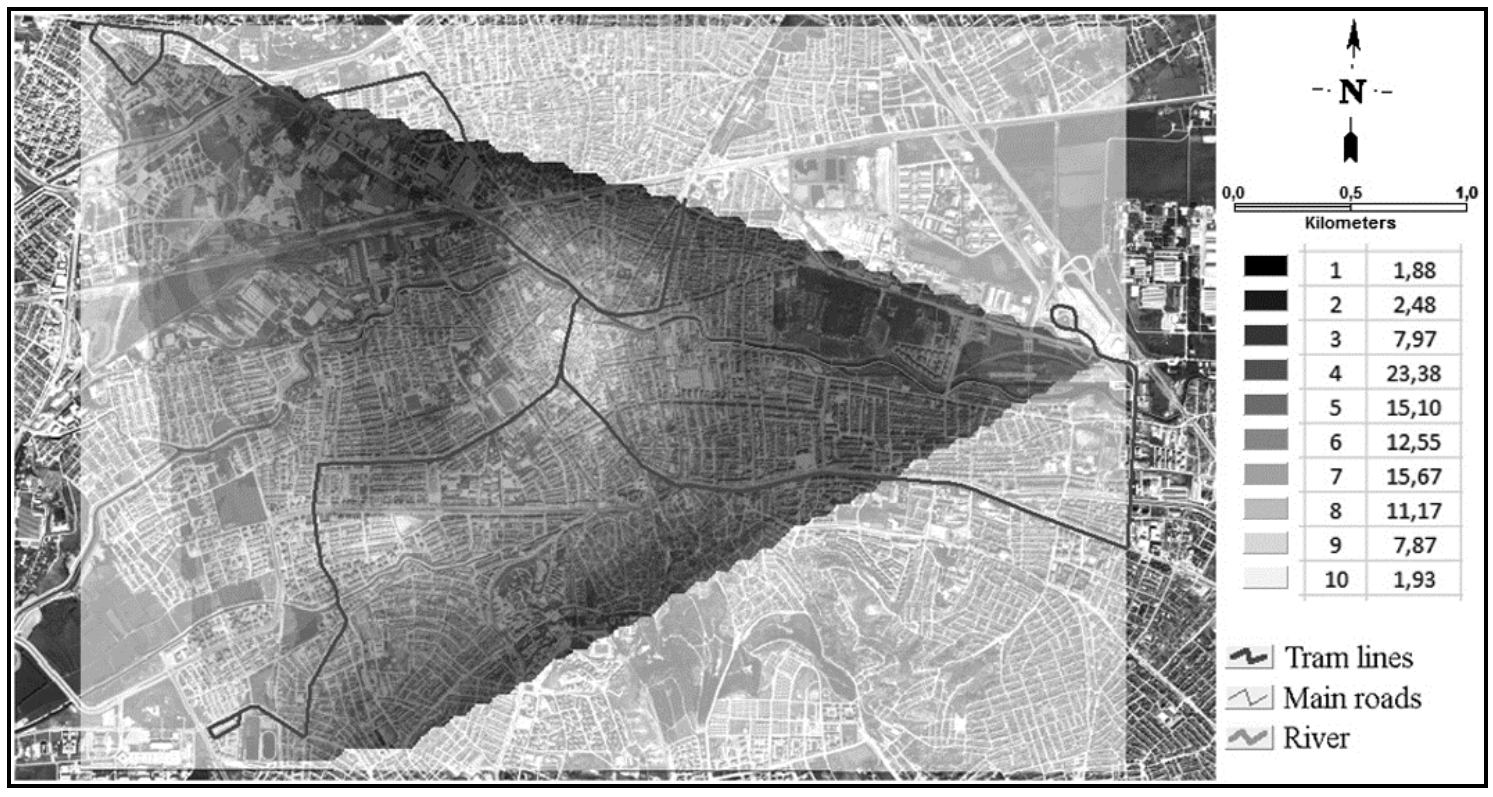

Figure 7. Superimposed map with satellite image and graded map of heavy metal pollutants

The final map, including the contribution to total heavy metal contamination of $\mathrm{Cd}$, $\mathrm{Cr}, \mathrm{Cu}, \mathrm{Fe}, \mathrm{Mn}, \mathrm{Ni}, \mathrm{Pb}$ and $\mathrm{Zn}$, illustrates that the mid and south western parts of the study area were more contaminated in terms of heavy metal contamination. According 
to statistical results, using values obtained from soil and roadside dust together give us a more accurate result than using them separately.

CIAPRG methodology is recommended for use in similar studies concerning any distribution characteristic assessment as an alternative solution for locational modeling with an interactive data base. CIAPRG methodology, suggested by the authors for this study, produced more efficient results than other conventional methods. In addition to this, CIAPRG methodology provides an assessment based on each rectified source, supported by the data base. Local authorities should be more cautious about buildings at the 8 to 10 graded scores and take necessary precautions in order to reduce risk (Figure 7).

\section{REFERENCES}

[1] Apeagyei, E., Bank, M.S., Spengler, J.D. (2011): Distribution of heavy metals in road dust along an urban-rural gradient in Massachusetts. - Atmos. Environ. 45: 2310-2323.

[2] Ayday, C., Altan, M., Nefeslioğlu, H., Canigür, A., Yerel, S., Tun, M. (2001): Geological and geotechnical exploratory survey report of Eskisehir city center for settlement, Anadolu University, Satellite and Space Science Research Institute. Eskişehir

[3] Bućko, M.S., Magiera, T., Johanson, B., Petrovský, E., Pesonen, L.J. (2011): Identification of magnetic particulates in road dust accumulated on roadside snow using magnetic, geochemical and micro-morphological analyses. - Environ. Pollut. 159: 1266-1276.

[4] Chen, X., Xia, X., Zhao, Y., Zhang, P. (2010): Heavy metal concentrations in roadside soils and correlation with urban traffic in Beijing, China. - J. Hazard Mater. 181: 640646.

[5] Christoforidis, A., Stamatis, N. (2009): Heavy metal contamination in street dust and roadside soil along the major national road in Kavala's region, Greece. - Geoderma 151: 257-263.

[6] Duong, T.T.T., Lee, B. (2011): Determining contamination level of heavy metals in road dust from busy traffic areas with different characteristics. - J. Environ. Manage. 92: 554-562.

[7] Kadi, M.W. (2009): Soil Pollution Hazardous to Environment: A case study on the chemical composition and correlation to automobile traffic of the roadside soil of Jeddah city, Saudi Arabia. - J. Hazard Mater. 168:1280-1283.

[8] Lee, C.S., Li, X., Shi, W., Cheung, S.C., Thornton, I. (2006): Metal contamination in urban, suburban, and country park soils of Hong Kong: A study based on GIS and multivariate statistics. - Sci. Total Environ. 356:45-61.

[9] Lu, X., Wang, L., Li, L., Lei, Y.K., Huang L., Kang, D. (2010): Multivariate statistical analysis of heavy metals in street dust of Baoji, NW China. - J. Hazard Mater. 173:744749.

[10] Madrid, L., Di'az-Barrientos, E., Madrid, F. (2002): Distribution of heavy metal contents of urban soils in parks of Seville. - Chemosphere 49: 1301-1308.

[11] Malkoc, S., Yazıc1, B., Koparal, A.S. (2010): Assessment of the levels of heavy metal pollution in roadside soils of Eskisehir, Turkey. - Environ. Toxicol. Chem. 29: 27202725.

[12] Nefeslioğlu, H., Tün, M., Ayday, C., Göktan M. (2003): Change detection of structures in the earthquake hazard zoning map of Eskisehir city, Turkey, by using satellite images, $2^{\text {nd }}$ Joint Workshop on Remote Sensing and Data Fusion over Urban Areas, URBAN, Berlin, Germany.

[13] Shi, G., Chen, Z., Xu, S., Zhang, J., Wang, L., Bi, C., Teng, J (2008): Potentially toxic metal contamination of urban soils and roadside dust in Shanghai, China. - Environ. Pollut. 156: 251-260. 
[14] Taner, P.A., Ma, H.L., Yu, P. (2008): Fingerprinting metals in urban street dust of Beijing, Shanghai, and Hong Kong. - Environ. Sci. Technol. 42: 7111-7117.

[15] Tun, M., Avdan, U., Altan, M., Ayday, C., Azdiken, S. (2004): NEHPR ground classification in Eskisehir city center with SCPT application, Turkey 16. International Geophysics Congress, MTA, Ankara, Turkey.

[16] USEPA. (2004): Envirionmental Protection Agency. A preliminary remediation goals table. Region 9, San Francisco, CA.

[17] USEPA. (2007): Microwave assisted acid digestion of sediments, sludges, soils and oils. Method 3051 A. Washington, DC.

[18] Wei, B., Yang, L. (2010): A review of heavy metal contaminations in urban soils, urban road dusts and agricultural soils from China. - Microchem. J. 94: 99-107.

[19] Xia, X., Chen, X., Liu, R., Liu, H. (2011): Heavy metals in urban soil with various types of land use in Beijing, China. - J. Hazard Mater. 186:2043-2050. 